\title{
Effects of an Anger Management and Stress Control Program on Smoking Cessation: A Randomized Controlled Trial
}

\author{
Bektas Murat Yalcin, MD, Mustafa Unal, MD, Hasan Pirdal, MD, and \\ Tevfik Fikret Karahan, PhD
}

Purpose: The purpose of this study was to investigate the effects of a cognitive behavioral therapy-oriented anger management and stress control program on smokers' quit rates.

Methods: Of 2348 smokers, 350 were randomly allocated into study and control groups ( $n=175$ each). An individualized therapy cessation technique was selected for each participant (combination of behavioral counseling, nicotine replacement therapy, and/or pharmacotherapy). The participants in the control group attended a standard quit program, whereas the study group also received an additional 5-session (90 minutes each) cognitive behavioral therapy-oriented program aimed at improving their anger and stress coping skills. At the beginning of the study, both groups were asked to complete the Trait Anger Scale (TAS) of the State and Trait Anger Scale and the Self-Confident (SCS) and Hopeless (HS) subscales of the Stress Coping Styles Inventory; pretest smoking status of both groups and their coping skills were compared with each other as soon as the program ended (post-test results) and after 3 and 6 months (first and second follow-up tests).

Results: Although there was no difference between pretest scores on the TAS $(P=.234), S C S(P=$ $.130)$, and HS $(P=.148)$ subscales, post-test results indicate that the study groups' TAS and HS scores decreased and SCS scores increased $(P<.001)$, whereas there was no change in the control group $(P>.05)$. The study group had a better quit level after 6 months compared with the control group $(44 \%$ vs $27.4 \% ; P<.001)$. The anger management and stress control program was found to have a significant effect on cessation (odds ratio, 2.09; 95\% confidence interval, 1.14-3.85).

Conclusion: The anger and stress coping skills program may increase the success of quitting smoking. (J Am Board Fam Med 2014;27:645-660.)

Keywords: Anger, Cognitive Therapy, Psychological Stress, Smoking, Smoking Cessation

The importance and effectiveness of primary care interventions in preventing smoking are well known. ${ }^{1}$ As part of health promotion activities, one priority has been to increase the success rates of smoking cessation. $^{2,3}$ However, up to $75 \%$ of smokers start to smoke again within 6 months, even though they re-

This article was externally peer reviewed.

Submitted 7 March 2014; revised 6 June 2014; accepted 16 June 2014.

From the Department of Family Practice, Ondokuz Mayıs University Medical School, Samsun, Turkey (BMY, MU); the Goynicek Town Integrated State Hospital, Turkey (HP); and the Educational Faculty, Psychological Counseling and Guidance, Ondokuz Mayıs University, Samsun, Turkey (TFK).

Funding: none.

Conflict of interest: none declared.

Corresponding author: B. M. Yalcin, MD, Department of Family Medicine, Faculty of Medicine, Ondokuz Mayıs University, University Hospital, Kurupelit/SAMSUN 55132, Turkey (E-mail: myalcin@omu.edu.tr). ceive behavioral support, nicotine replacement therapy (NRT), or drugs (bupropion or varenicline). ${ }^{4}$ Many studies have been performed to understand the interacting physiological and psychological factors involved in relapse. ${ }^{5}$ Some sociodemographic risk factors (sex, education level, marital status, living alone, and income) have been identified. Nicotine-a very potent psychological and neurological stimulant that influences behaviors, emotions, and mood-is implicated as the main factor responsible for initiation, maintenance, and relapse in terms of smoking. ${ }^{6-9}$ In recent years a strong relation between anger, stress, and smoking has been noticed. ${ }^{10,11}$ Smokers report that they smoke more when they are stressed, angry, anxious, or sad and that they expect that smoking will alleviate these negative moods. ${ }^{12}$ There is strong evidence that nicotine reduces emotions of stress and 
anger because deprivation causes increases in feelings of anger and stress, despite whether they are amplified by other distressing withdrawal symptoms. ${ }^{13}$ Several different interacting models, such as a direct effects mechanism (opioid and reward pathway models) and moderator (restoration of homeostasis model) and mediator effects [situation by trait adaptive response (STAR) model] have been investigated to explain the relation between nicotine, stress, and anger. ${ }^{14-18}$

Despite all the evidence concerning the relationship between smoking, anger, and stress, the effect of this relationship on relapse is not well documented. Some recent studies noted that individuals with high levels of trait anger and stress are more prone to start smoking again. ${ }^{19,20}$ More recent studies revealed that smokers with insufficient anger management and stress control skills are more vulnerable to relapse. $^{21,22}$ These data reflect the importance of effective anger management and stress control skills in dealing with nicotine abstinence and successful maintenance of quitting smoking. Support for anger and stress is used in many quit-smoking counseling activities. $^{23}$ These activities, however, do not address the actual problem. Without improved anger management and stress control skills, smokers who have since quit are at a high risk of relapse in the face of adverse daily life experiences (which may cause high levels of anger and stress) whenever they need the support previously provided by smoking. ${ }^{24}$ Anger management and stress control skills are regarded as being in the main domains of emotional intelligence and can be upgraded and promoted with proper cognitive behavioral approaches. ${ }^{25}$ It would, therefore, be a logical assumption that improving these skills results in an increase in smokers' quit rates, which may help them to avoid relapse, not only in the short term but also in the mid-term. To test this hypothesis, we designed a 5 -session anger management and stress control program to promote these skills in smokers who are willing and ready to quit. This study investigates the effect of a cognitive behavior-oriented anger management and control program designed to be applied in primary care settings dealing with quitsmoking activities to increase quit rates.

\section{Materials and Methods \\ Design}

The study was designed as a randomized controlled trial between March 2010 and December 2011. It was performed at the Ondokuz Mayis University
Medical Faculty Department of Family Practice Smoking Quittance Clinic, Turkey. Before the study began, a power analysis was conducted to calculate the number of participants within different treatment groups. Based on the literature, we assumed standard deviation of 22, 8 levels, a target power of 0.8 , and a maximum difference of 20 . Based on that analysis, we calculated a minimum number of 28 participants in each treatment group. To minimize the risk of affecting the study outcomes, we decided to investigate the effects of this program on smokers who had never tried to quit before. Relapsed smokers might have experienced some of the cessation strategies and had a negative attitude toward the methods they had used previously. The other criteria for inclusion in the study were willingness to take part in and attend all sessions, age $>18$ years, intent to quit smoking within 6 months, smoking $>10$ cigarettes a day, not taking any psycho-regulatory medication (antidepressants, anxiolytics, or antipsychotics), not having any psychiatric illnesses, not being pregnant or breastfeeding, and applying all the program session content for 6 months.

In our clinic, smokers are placed on a waiting list for the following month after their initial sociodemographic, health, and smoking features are investigated. After we announced that a cognitive behavioral therapy-oriented anger management and stress control program aiming to increase these skills of smokers was to be implemented, we selected smokers who fulfilled the research criteria for the study and control groups from these waiting lists. Each month, a new study group (a total of 12 different study groups) and control group (a total of 12 different control groups) were added to the research; participants were selected from the previous month's waiting list.

To obtain optimal efficiency from cognitive behavioral treatment (enough experiences to be shared, stimuli for discussion, etc.), the number of participants in the groups had to be limited to approximately 20. This would have limited our research to a single study and control group. Therefore we decided to form each month new study (12 in total) and control (12 in total) groups limited to approximately 20 participants selected at random from our clinic's waiting list. The first study and control subgroups were selected from the waiting list of February 2010, and the 12th and last subgroups from the January 2011 list. The total 
study population consisted of 2348 smokers admitted to our clinic between February 2010 and January 2011. Of these, 350 smokers (175 smokers in each group) were selected for the research. To perform basic randomization in groups, participants who fulfilled the study criteria and were on the previous month's waiting list were divided into 2 different lists by sex in order of application. First, the male and female smokers at the top of both lists were assigned to the study subgroup, the second smokers on both lists to the control subgroup, the third to the study subgroup, the fourth to the control subgroup, and so on, until they were equally divided. The remaining smokers on the waiting list who did not meet the study criteria $(\mathrm{n}=1418)$ or who were not interested in participating in the research $(\mathrm{n}=580)$ were administered our clinic's standard treatment procedure (control group treatment program), consisting of approximately 3 months of treatment and follow-up. An informed consent form was obtained from each participant, and a confidentiality contract was signed by study group members.

At the beginning of the program, each participant in the study and control subgroups was asked to respond to the Fagerstrom Test for Nicotine Dependence (FNDT), the State Trait Anger Inventory, and the Styles of Coping with Stress Inventory (pretests). Pretests were collected from subgroups between March 2010 (first study and control subgroups) and January 2011 (12th study and control subgroups). Our clinic's standard quitting procedure was applied to both subgroups, whereas the 5-week anger management and stress control coping program was applied to the study subgroups alone. Smoking status of participants in both subgroups, together with their skills, were compared and recorded as soon as the program ended, 30 to 35 days from their first visits (post-test results). Post-test results were collected from subgroups between May 2010 (first study and control subgroups) and March 2011 (12th study and control subgroups). The same data were collected the third and sixth months after post-tests were administered to both subgroups (first and second follow-up tests). First follow-up tests were collected between September 2010 (first study and control subgroups) and August 2011 (12th study and control subgroups) and the second follow-up tests between November 2010 and December 2011 (including relapsed participants). At the end of the study, the results from the participants in these subgroups were pooled and evaluated as a single study group and single control group. Although the participants in the study subgroups knew that they were in the anger management and stress control program, the data collectors were blind when applying the tests. Relapsed participants reenlisted in our clinic for a new round of treatment 6 months later.

The participants were expected not to smoke for any reason after the contracted quit day. Smoking status of patients was established by self-report and assessment of carbon monoxide with an inhaler. Participants who relapsed on just 1 or 2 occasions were not excluded from the study. Participants with readings of $\leq 10 \mathrm{ppm}$ carbon monoxide were regarded as smoking free. ${ }^{26}$ Participants' smoking status was investigated 4 times. The first investigation was performed between the 7 th and 10th days after the contracted quit day (post-test). The second investigation was the 30th day after the quit day, the $3 \mathrm{rd}$ was at the 90th day (1st follow-up test), and the 4th was at approximately the 180th day (2nd follow-up test). A flowchart of the study procedure administered to all study and control subgroups is shown in Figure 1. The study was performed in all subgroups in this chronological order, with no more than 3 or 4 days' delay because of differences in quitting times and some national holidays.

Both groups received a 40-minute session of the same workshop on their first visit. Participants in the control group received nearly 150 minutes of individualized face-to-face treatment (in approximately 10 visits) for 6 months (control groups' treatment program). Participants in the study group received 630 minutes of group $(5+2$ sessions) and 100 minutes of individualized (10 visits) face-to-face treatment for 6 months (anger management and stress control program). We calculated that approximately 440 work hours (for 175 participants) were needed for the control group and nearly 420 work hours were needed for the study group in 6 months.

\section{Control Group Treatment Program (Clinic's Standard Program)}

All subjects took part in several types of smoking cessation activities according to their smoking status, dependency level, and indications. ${ }^{27-30}$ This program includes a group workshop, face-to-face interventions 
Figure 1. Flowchart of the study procedure administered to all participants in the study and control groups (a total of 12 groups); a new study and control group were included every month between March 2010 and February 2011.

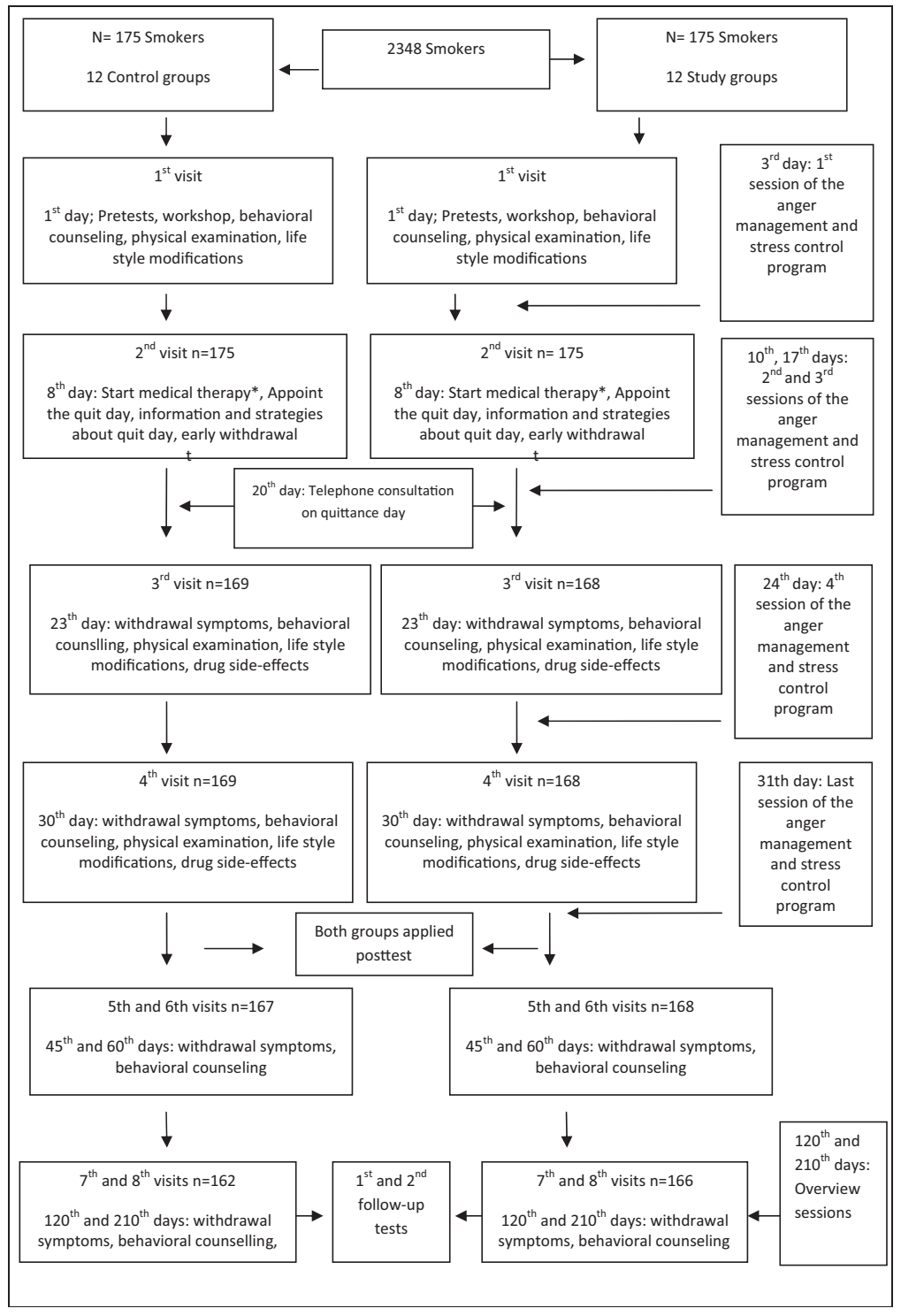

aimed at maintaining lifestyle changes, NRT, and pharmacotherapy. Patients who apply to the Ondokuz Mayıs University Family Practice Smoking Cessation Clinic are enrolled in an average 3-month smoking cessation program. Approximately 10 interviews (4 in the first month, 3 in the second, and 3 in the third) are conducted during the program. If necessary, one visit per month can be planned. Appointments are made to form groups of 20 patients each.

During the first meeting, a workshop is held at which smoking cessation techniques and nicotine addiction are discussed with the group for approximately 1 hour. At this workshop, members share previous smoking cessation experiences. All group members are encouraged to share their experiences and thoughts concerning how they started smoking, the benefits of quitting, any close friends or relatives who were harmed by smoking, any close friends or relatives who successfully quit smoking, and previous attempts to quit (How long did you quit for? What went wrong? Which method was used?). In the next step, a short, interactive presentation is given to consolidate negative emotions against smoking and reinforce the desire to quit. In this part of the session, strategies for smoking cessation, drug therapies including NRT and behavioral approaches to dealing with addiction, are dis- 
cussed. To avoid withdrawal symptoms (mostly coping with anger and stress), basic techniques (increase physical activity, change one's environment, the effect of relaxing music, hobbies, and deep breathing, etc.) are discussed for at least $20 \mathrm{~min}-$ utes. Patients first are asked to perform some lifestyle modifications and change their smoking habits (discussion and handouts). These changes aim to prepare the patient for the quitting day. They include changing the cigarette brand used, not smoking for 90 minutes after waking up, smoking only after meals or with tea or coffee (if these usually accompany smoking), avoiding offering and accepting cigarettes from other people, smoking alone (if being in a group triggers smoking), changing one's usual smoking places (at home, work, etc.), refraining from alcohol intake for 3 months (if smoking accompanies alcohol use), and, finally, increasing the amount of daily physical exercise (half hour, moderate). They are finally asked to find a quit buddy from their workshop group for the future quitting process; then the workshop is concluded.

On the same day, each patient is privately interviewed for a minimum of 20 minutes, and a general physical examination (anthropometric parameters included) is performed. The principles of motivational interviewing are used during this session. ${ }^{31}$ Each smoker is given an individualized behavioral counseling session lasting 20 minutes. In this first step, the smoker is encouraged to make lifestyle changes, and the next appointment is scheduled, usually for a week to 10 days later. At the second appointment, lifestyle changes are evaluated, the basic techniques for withdrawal symptoms are revised face to face, and a quit day is agreed on (generally 10 to 12 days later). Pharmacological treatment (drugs) begins here. If the patient wishes to use NRT, he or she is recommended to start on the quit day. On the quit day, a telephone call is made to the patient in an attempt to increase motivation. After 2 days of quitting, another interview is conducted if possible. In these interviews, nicotine withdrawal symptoms, strategies to overcome them, side effects or any other problems associated with drugs (if used), and reinforcement of motivation are discussed. Subsequently, similar interviews are conducted every 10 to 15 days.

\section{Treatment Groups}

There were 4 different treatment groups. The first group was treated with behavioral counseling (BC; motivational interviewing with lifestyle modification) only, the second group received BC with NRT, the third received $\mathrm{BC}$ with bupropion, and the fourth BC with varenicline. Smokers' choice of treatment group was discussed with them based on their smoking history, FNDT scores, and indications and contraindications set out by the Turkish Ministry of Health. NRT is mostly used with smokers with FNDT scores $<3$, and varenicline or bupropion with smokers with FNDT scores $\geq 3$. All drugs were provided free for 3 months during the study period by the Ministry of Health. Written consent was obtained from all patients before initiating pharmacotherapy. NRT is used in doses of $21 \mathrm{mg}$, either as gum or patches, for as long as necessary. Bupropion is recommended at $150 \mathrm{mg}$ for the first 3 days of therapy and $300 \mathrm{mg}$ from the fourth day, usually for 3 months. Varenicline is used at $500 \mathrm{mg}$ for the first 3 days, $1000 \mathrm{mg}$ between the fourth and seventh days, and $2000 \mathrm{mg}$ from the eighth day, usually for 3 months.

\section{Anger Management and Stress Control Skills Training Program}

The cognitive behavioral therapy-oriented anger management and stress control program was applied to the study group for 5 weeks in 90-minute sessions as soon as the standard cessation program was initiated (2 days after the first interview). We designed a 5 -session program (90 minutes each). The program is structured along eclectic, educational, and didactic experimental principals in accordance with time limitations. Many resources were used to design the program, as mentioned elsewhere. $^{32}$ The program content is presented in Appendix 1. Participants are expected to acquire the following skills: ability to notice clues to anger and stress; ability to recognize physical, emotional, and behavioral responses to sources of stress and anger; ability to learn and use techniques of relaxation and proper breathing for the control of stress in daily life; to gain awareness of anger and stress-related situations, such as uncontrolled behavior, physical assaults, or regrettable behavior; to gain awareness of the damaging effects of stress and anger on relationships, overeating, smoking, or drug use to appease anger and stress together with associated physical and legal problems; ability to recognize anger and stress-related negative automatic thoughts, and core and adjacent beliefs, and the ability to detect and define negative emotions that 
accompany these as they arise; ability to use various skills and cognitive restructuring to control stress and anger; ability to recognize cognitive diversions; ability to share emotions without aggression; ability to use effective communication, social interaction, time management, use of humor, changes in the environment, and so on; ability to express anger and other negative emotions with "I" language; ability to use effective listening skills and notice inappropriate listening reactions; ability to control stress and anger and to display willingness to maintain communication and create empathy in an attempt to establish understanding at times of conflict. As usual in cognitive behavioral-oriented therapy, 2 additional sessions were held at the third and sixth months aiming to overview the content of the anger management and stress control program and share participants' experiences. Before these sessions, the first and second follow-ups using the Trait Anger Scale (TAS) of the State and Trait Anger Scale and the Self-Confident subscale (SCS) and Hopeless subscale (HS) of the Stress Coping Styles Inventory were applied to the participants in the study group.

\section{Tools}

\section{Fagerstrom Test for Nicotine Dependency}

The FNDT is a 6-item self-report scale frequently used worldwide to determine levels of nicotine addiction. ${ }^{33}$ Although the test is actually modified from the Fagerstrom Tolerance Questionnaire, it has better internal consistency and is more easily answered. In terms of the overall logic of this test, it is based on number of cigarettes smoked and length of smoking-free periods. The instrument yields a dependency score between 0 (low) and 10 (high).

\section{State Trait Anger Scale}

Developed by Spielberger et $a{ }^{34},{ }^{34}$ the State Trait Anger Scale has 2 main subscales, the TAS, consisting of 10 self-reported items, and the Anger Expression Scale, which has 3 different subscales of 8 self-reported items (a total of 24 items). We used TAS scores as variables indicating trait anger level for this research. An individual can score between 0 and 40 on the TAS. Higher scores on the TAS indicate that the individual's trait anger level is high. Validity and reliability of the Turkish version of the test was investigated by Ozer. ${ }^{35}$ Cronbach $\alpha$ values have been calculated as 0.90 for the State
Trait Anger Scale and between 0.82 and 0.90 for the subscales.

\section{Styles of Coping with Stress Inventory}

This inventory is based on the Ways of Coping Styles questionnaire designed by Folkman and Lazarus. ${ }^{36}$ Sahin and Durak ${ }^{37}$ worked on the Turkish version of this scale and developed the Styles of Coping with Stress Inventory. This consists of 30 self-reported items on a 4-point Likert scale. The questionnaire has 5 subscales indicating different approaches to coping with stress: self-confident approach (7 items), optimistic (5 items), hopeless (8 items), seeking social support (4 items), and submitted ( 6 items). Cronbach $\alpha$ values for the subscales were calculated as $0.92,0.86,0.88,0.94$, and 0.84. The overall Cronbach $\alpha$ value for Styles of Coping with Stress Inventory is 0.90. A higher scores on any subscale indicates that the subject uses that approach to cope with stress. We used the self-confident and hopeless subscales in our study. The individual can score from 0 to 21 on the SCS and from 0 to 24 on the HS. Subjects with higher scores on the SCS are regarded as using effective (problem-based) stress coping skills. However, subjects with higher scores on the HS are regarded as using ineffective (emotion-based) coping skills.

\section{Statistical Analyses}

The results of the items (pretest, post-test, first follow-up and second follow-up of TAS, SCS, and HS) were regarded as independent variables. The relations between demographic, smoking features, and results of the items were investigated using the $\chi^{2}$ test, Pearson correlation analysis, the independent samples $t$ test, and 2-way repeated measures analysis of variance. Two proportions tests were used to analyze the difference between cessation success rates between the treatment groups. Independent factors affecting smoking cessation were investigated using logistic regression analyses. Minitab version 10 (Minitab, Inc.; available from: http://www.minitab.com/en-us/ downloads/) was used for power analyses and the 2 proportions test. All the remaining statistical analyses were performed on SPSS version 13.0 (SPSS, Inc., Chicago, IL). $P<.05$ was considered statistically significant.

\section{Results}

Of the original 350 subjects included, 328 (93.7\%) completed the study (22 dropped out, 13 from the 
study group). All the dropouts were regarded as relapsed. Data from the dropouts were excluded from the point at which they left the study. Among these dropouts, 15 participants experienced severe drug side effects (eg, abdominal pain, vomiting, atopic dermatitis) and their treatment had to be changed. We also were unable to contact 7 relapsed participants during data collection.

The epidemiologic and clinical features of the 2 groups and their statistical relations are shown in Table 1. Pretest, post-test, first follow-up, and second follow-up scores and their statistical relations within (study or control) or between groups (study and control) are presented in Table 2. There was no statistical difference between TAS, SCS, and HS pretest scores in terms of age, FNDT score, or package/year values in either group. However, women had higher pretest SCS scores compared with men $(t=2771 ; P=.006)$. Pretest, post-test, and first and second follow-up results for TAS, SCS, and HS were not statistically different in the control group $(\mathrm{F}=1.201, P=.234 ; \mathrm{F}=1.018, P=$ .130 ; and $\mathrm{F}=1.616, P=.148$, respectively). They were, however, different in the study group $(\mathrm{F}=$ $25.041, P<.001 ; \mathrm{F}=13.506, P<.001 ;$ and $\mathrm{F}=$ $3.829, P<.01$, respectively). The profile plots of the study and control groups' pretest, post-test, and the first and second follow-up mean TAS scores are shown in Figure 2, those for SCS in Figure 3, and those for HS in Figure 4. Although there was no statistical difference between the pretest scores of the 2 groups at the beginning of the study, the study group had lower scores on the TAS ( $t=$ 6.569; $P<.001)$ and HS $(t=2.114 ; P=.03)$ and higher scores on the SCS $(t=6.918 ; P<.001)$, according to the post-test results. The first follow-up and second follow-up scores of the 2 groups' TAS ( $t=8.851$ and 12.798 , respectively; $P<.001$ for both), SCS $(t=10.151$ and 10.255 , respectively; $P<.001$ for both), and HS ( $t=5.564$; $P<.01$ and $t=3.897 ; P=.02$, respectively) results were statistically different from each other. The pretest TAS and SCS scores of the relapsed smokers compared with the smokers who quit were both statistically higher in the control group (TAS: $22.7 \pm 3.8$ vs $20.12 \pm 2.4 ; t=4.377, P<.001$ and SCS: $49.83 \pm 5.8$ vs $46.72 \pm 5.1 ; t=3.181 ; P<$ .001). This significance was not observed in the study group, however $(P>.05)$. Although there was no difference in the pretest scores for TAS, SCS, and HS, post-test SCS scores were higher in the $\mathrm{BC}+$ varenicline (mean, $14.10 \pm 1.2 ; \mathrm{F}=$ 2.377; $P=.005)$ and $\mathrm{BC}+$ bupropion groups (mean, $14.31 \pm 0.9 ; \mathrm{F}=2.589 ; P=.003$ ) compared with the BC only (mean, $13.50 \pm 1.3$ ) and NRT (mean, $11.72 \pm 0.8$ ) treatment groups in the study

Table 1. Clinical and Epidemiological Features of the Two Groups

\begin{tabular}{|c|c|c|c|c|c|}
\hline Variables & Study Group & Control Group & $P$ Value & $x^{2}$ & $t$ \\
\hline \multicolumn{6}{|l|}{$\operatorname{Sex}(n)$} \\
\hline Men & 87 & 89 & .102 & 0.686 & \\
\hline Women & 88 & 86 & & & \\
\hline Age (years) & $35.25 \pm 21.25$ & $37.19 \pm 51.14$ & .201 & & 0.807 \\
\hline Marital status & & & .098 & 0.143 & \\
\hline Single & $11(8)$ & $10(6)$ & & & \\
\hline Married & $140(86)$ & $147(88)$ & & & \\
\hline Widow & $6(4)$ & $3(2)$ & & & \\
\hline Divorced & $5(3)$ & $6(4)$ & & & \\
\hline Education year & $9.25 \pm 1.8$ & $9.8 \pm 1.0$ & .117 & & 0.568 \\
\hline Fagerstrom nicotine Dependency score & $5.84 \pm 2.32$ & $5.67 \pm 1.78$ & .157 & & 1.021 \\
\hline Package/year & $26.2 \pm 2.4$ & $24.1 \pm 3.9$ & 0.361 & & 0.972 \\
\hline Mean years of active smoking & $16.4 \pm 2.7$ & $15.9 \pm 1.8$ & 0.512 & & 0.954 \\
\hline Cessation method selected & & & 0.213 & 0.705 & \\
\hline BC only & $29(16.5)$ & $31(17.7)$ & & & \\
\hline $\mathrm{BC}+\mathrm{NRT}$ & $46(26.2)$ & $42(24.0)$ & & & \\
\hline $\mathrm{BC}+$ bupropion & $45(25.7)$ & $45(25.7)$ & & & \\
\hline $\mathrm{BC}+$ varinicline & $55(31.4)$ & $57(32.5)$ & & & \\
\hline
\end{tabular}

Data are $\mathrm{n}(\%)$ or mean \pm standard deviation unless otherwise indicated.

BC, behavioral counseling (motivational interview with life style modification); NRT, nicotine replacement therapy. 
Table 2. Mean Pretest, Post-Test, and Follow-up State Trait Anger Inventory (TAS), Self-Confident Approach Subscale (SCS), and Hopeless Subscale (HS) Scores Between the Two Groups

\begin{tabular}{|c|c|c|c|c|c|c|c|c|c|c|}
\hline & \multicolumn{2}{|c|}{ Pretest } & \multicolumn{2}{|c|}{ Post-test } & \multicolumn{2}{|c|}{ First Follow-up } & \multicolumn{2}{|c|}{ Second Follow-up } & \multirow[b]{2}{*}{$P$ Value* } & \multirow[b]{2}{*}{$F$} \\
\hline & Mean $\pm \mathrm{SD}$ & $\mathrm{n}$ & Mean $\pm \mathrm{SD}$ & $\mathrm{n}$ & Mean $\pm \mathrm{SD}$ & $\mathrm{n}$ & Mean $\pm \mathrm{SD}$ & $\mathrm{n}$ & & \\
\hline \multicolumn{11}{|l|}{ TAS } \\
\hline Study & $22.48 \pm 3.7$ & 175 & $20.66 \pm 4.3$ & 169 & $19.3 \pm 4.0$ & 167 & $18.40 \pm 3.5$ & 163 & $<.001$ & 25.041 \\
\hline Control & $22.13 \pm 3.7$ & 175 & $23.44 \pm 3.5$ & 168 & $22.9 \pm 3.5$ & 168 & $23.2 \pm 3.5$ & 166 & .234 & 1.201 \\
\hline$P$ Value $^{\dagger}$ & .721 & & $<.001$ & & $<.001$ & & $<.001$ & & & \\
\hline$t$ & 0.932 & & 6.569 & & 8.851 & & 12.798 & & & \\
\hline \multicolumn{11}{|l|}{ SCS } \\
\hline Study & $10.43 \pm 3.4$ & 175 & $13.45 \pm 3.5$ & 169 & $13.42 \pm 3.6$ & 167 & $13.37 \pm 3.6$ & 163 & $<.001$ & 13.506 \\
\hline Control & $11.17 \pm 4.1$ & 175 & $10.86 \pm 3.0$ & 168 & $10.54 \pm 3.3$ & 168 & $10.49 \pm 3.0$ & 166 & .130 & 1.018 \\
\hline$P$ Value $^{\dagger}$ & .098 & & $<.001$ & & $<.001$ & & $<.001$ & & & \\
\hline$t$ & 1.023 & & 6.918 & & 10.151 & & 10.255 & & & \\
\hline \multicolumn{11}{|l|}{ HS } \\
\hline Study & $11.55 \pm 4.6$ & 175 & $10.27 \pm 4.0$ & 169 & $11.64 \pm 4.98$ & 168 & $10.15 \pm 4.1$ & 163 & $<.01$ & 3.829 \\
\hline Control & $11.62 \pm 4.5$ & 175 & $11.35 \pm 4.7$ & 168 & $12.05 \pm 5.1$ & 168 & $11.54 \pm 4.2$ & 166 & .148 & 1.616 \\
\hline$P$ Value $^{\dagger}$ & .121 & & .03 & & $<.01$ & & .02 & & & \\
\hline$t$ & 0.987 & & 2.114 & & 5.564 & & 3.897 & & & \\
\hline
\end{tabular}

*The statistical relation within study or control groups' pretest, post-test, first follow-up, and second follow-up of mean TAS, SCS, and HS scores.

${ }^{\dagger}$ The statistical relation between study or control groups' pretest, post-test, first follow-up, and second follow-up of mean TAS, SCS, and HS scores.

group. The same relation also was observed in the control group. Post-test SCS scores were affected among the treatment types; varenicline exhibited the highest mean (mean,12.45 $\pm 1.0 ; \mathrm{F}=16.946$; $P<.001)$ compared with the other groups.
The study group had a better quit rate at the end of the study compared with the control group (44\% vs $\left.27.4 \% ; \chi^{2}=9.816 ; P<.001\right)$. Relapse rates in the first week and the first, third, and sixth months based on quit methods between

Figure 2. Comparison of estimated marginal means of pretest, post-test, and first and second follow-up tests for Trait Anger Scale of the State and Trait Anger Scale in the control and study groups.

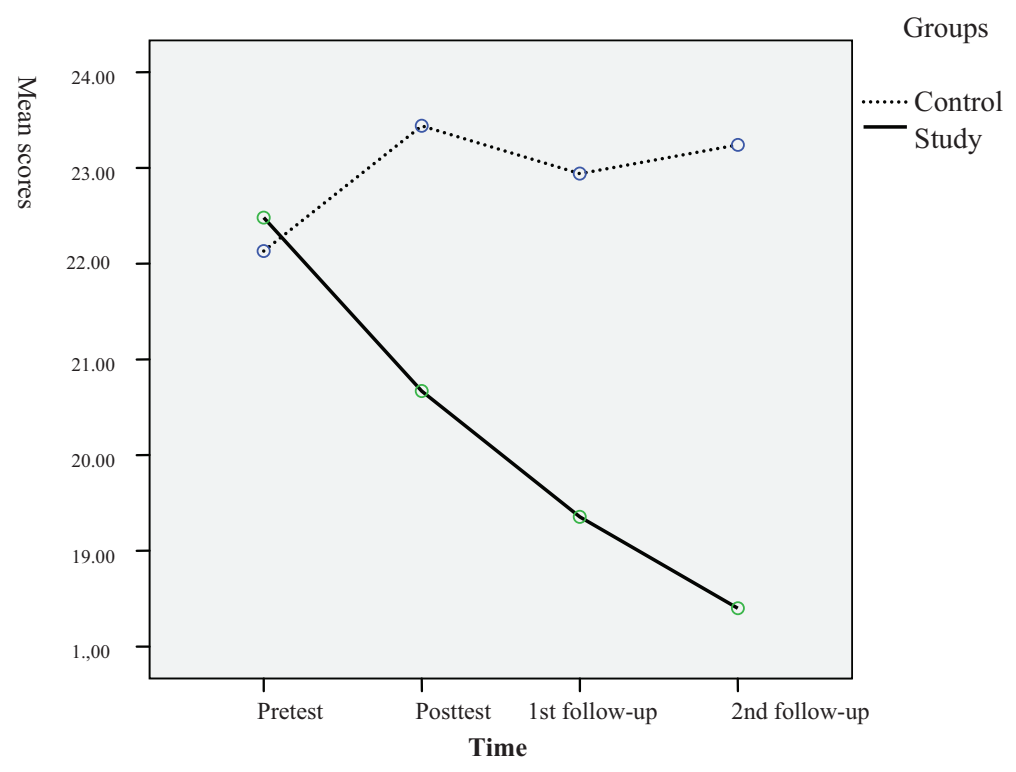


Figure 3. Comparison of estimated marginal means of pretest, post-test, and first and second follow-up tests for hopeless subscale of the Stress Coping Styles Inventory in the control and study groups.

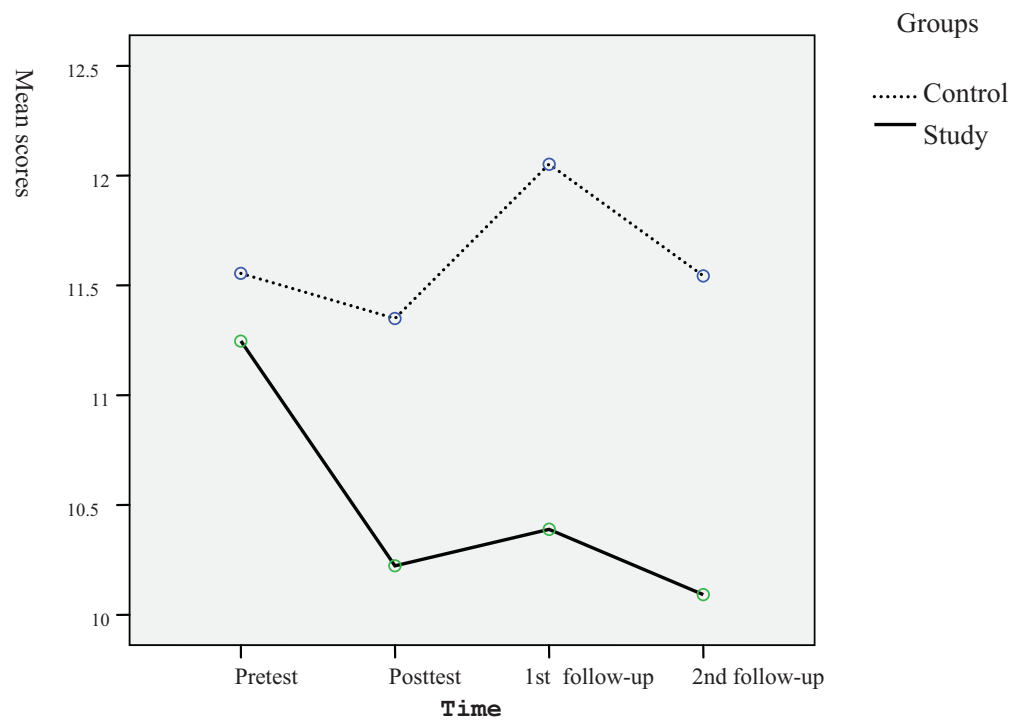

the study and control groups are presented in Table 3 . In the study group, success rates were $38 \%$ in the BC group $(\mathrm{n}=11)$, NRT $46.3 \%$ in NRT ( $\mathrm{n}=21), 42.3 \%$ in bupropion $(\mathrm{n}=19)$, and $46.4 \%$ in varenicline $(n=26)$ over the 6 -month period. The equivalent results in the control group were $16.2 \%$ in the BC group $(\mathrm{n}=5)$, $23.8 \%$ in NRT $(\mathrm{n}=10), 28.8 \%$ in bupropion $(\mathrm{n}=13)$, and $35.2 \%$ in varenicline $(\mathrm{n}=20)$. Quit rate was not correlated with the selected cessa- tion method $(P>.05)$ at the end of the 6 months in either group. In the study group, 98 participants $(56 \%)$ relapsed. Most of the relapses occurred in the first week and between the second week and first month. In the study group, one third of relapses occurred in the first week $(\mathrm{n}=$ $33,33.6 \%)$, and another 27 smokers (27.5\%) relapsed between the second week and the first month $(61.1 \%$ of all relapses). The rates in the control group were $74(58.8 \%)$ in the first week

Figure 4. Comparison of estimated marginal means of pretest, post-test, and first and second follow-up tests for self-confident subscale of the Stress Coping Styles Inventory in the control and study groups.

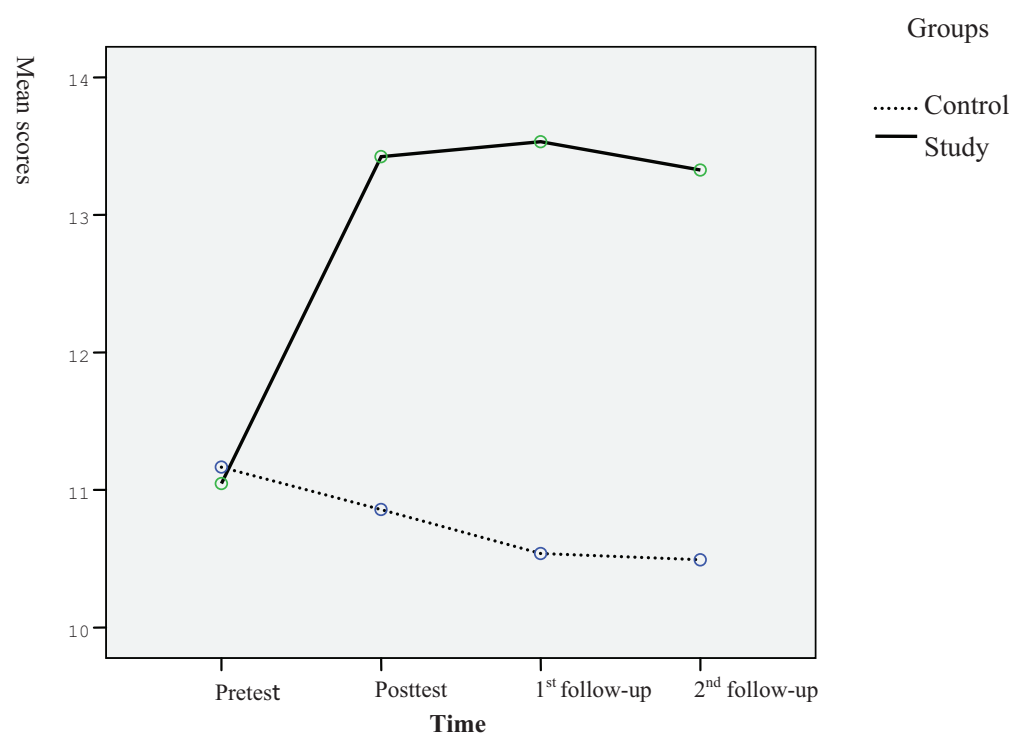


Table 3. Relapse Rates of the Participants in Study and Control Groups According to Cessation Method in the First Week and First, Third, and Sixth Months

\begin{tabular}{|c|c|c|c|c|c|c|c|c|c|c|}
\hline \multirow[b]{2}{*}{ Time } & \multicolumn{5}{|c|}{ Study Group } & \multicolumn{5}{|c|}{ Control Group } \\
\hline & BC & $\begin{array}{l}\text { BC + } \\
\text { NRT }\end{array}$ & $\begin{array}{c}\text { BC }+ \\
\text { Bupropion }\end{array}$ & $\begin{array}{c}\mathrm{BC}+ \\
\text { Varenicline }\end{array}$ & $\begin{array}{c}P \\
\text { Value }\end{array}$ & BC & $\begin{array}{l}\text { BC + } \\
\text { NRT }\end{array}$ & $\begin{array}{c}\text { BC + } \\
\text { Bupropion }\end{array}$ & $\begin{array}{c}\mathrm{BC}+ \\
\text { Varenicline }\end{array}$ & $\begin{array}{c}P \\
\text { Value }\end{array}$ \\
\hline First week & $9(50)$ & $14(50)$ & $12(46.1)$ & $16(55.1)$ & .231 & $17(65.3)$ & $18(56.2)$ & $20(62.5)$ & $19(51.3)$ & .125 \\
\hline Second week to first month & $6(33.3)$ & $8(32)$ & $6(23)$ & $7(24.1)$ & .158 & $6(18.7)$ & $7(21.8)$ & $6(18.7)$ & $10(27)$ & .098 \\
\hline First to third month & $2(11.1)$ & $1(4)$ & $6(23)$ & $3(10.3)$ & .02 & $2(6.2)$ & $4(12.5)$ & $4(12.5)$ & $5(13.5)$ & .03 \\
\hline Third to sixth month & $1(5.5)$ & $2(8)$ & $2(7.6)$ & $3(10.3)$ & .568 & $1(3.1)$ & $3(9.3)$ & $2(6.2)$ & $3(8.1)$ & .215 \\
\hline Total relapse rate & $18(62)$ & $25(53.1)$ & $26(57.7)$ & $29(53.7)$ & .012 & $26(83.8)$ & $32(76.1)$ & $32(69.5)$ & $37(66)$ & .009 \\
\hline
\end{tabular}

BC, behavioral counseling (motivational interview with life style modification); NRT, nicotine replacement therapy.

and another $29(22.8 \%)$ between the second week and the first month (81.6\% of all relapses).

A logistic regression model was used to investigate the factors affecting quitting smoking. First, the statistical significance between different variables (age, sex, marital status, application to join the anger management and stress control program, initial FNDT scores, packs per year, number of previous attempts at quitting, treatment groups, and pretest and post-test TAS, SCS, and HS scores) and cessation success was investigated. The final model was established from statistically significant correlations, application to the anger management and stress control program, and pretest and posttest TAS, SCS, and HS scores. This model is described in Table 4. According to this model, participation in the anger management and stress control program, low scores on the post-test TAS and HS, and higher scores on the post-test SCS were identified as factors in effective cessation for 6 months.

\section{Discussion}

The most striking result of this study was the higher quit rates in the study group compared with the control group (44\% vs $27.5 \%$ ) over 6 months. The National Institute for Health and Clinical Excellence regards a $27.5 \%$ quit rate in the first 6 months as favorable. ${ }^{29}$ However, the quit rate in our study group considerably exceeded these expectations. Our findings reveal that, compared with the control group, the participants in the study group who took part in the anger management and stress control program improved their self-coping anger and stress skills. However, the control group's trait anger scores were slightly elevated, and the percentage of participants using effective stress coping strategies remained unaltered during the study period, as confirmed in other studies. ${ }^{38,39}$ These data confirm the effectiveness of the program in promoting these skills, which may account for the increased quit rates in our study group. Our study highlights the importance of anger and stress

Table 4. Logistic Regression Model Investigating the Factors for Quitting Smoking

\begin{tabular}{lcccccc}
\hline Factors & B & Standard Error & Wald & $P$ Value & Exp(B) & $95 \%$ CI for EXP (B) \\
\hline Participating in the program* & 0.741 & 0.310 & 5.701 & $\mathbf{. 0 0 1}$ & 2.091 & $1.148-3.851$ \\
Pre-TAS & -0.054 & 0.30 & 3.154 & .076 & 0.947 & $0.893-1.006$ \\
Post-TAS & -0.135 & 0.034 & 12.202 & $\mathbf{0 . 0 0 1}$ & 0.889 & $0.810-1.049$ \\
Pre-SCS & 0.010 & 0.034 & 0.081 & .776 & 1.010 & $0.945-1.078$ \\
Post-SCS & 0.120 & 0.047 & 6.407 & $\mathbf{. 0 1}$ & 0.887 & $0.808-0.973$ \\
Pre-HS & 0.029 & 0.026 & 1.178 & .278 & 1.029 & $0.997-1.084$ \\
Post-HS & -0.091 & 0.029 & 4.146 & $\mathbf{. 0 3}$ & 0.989 & $0.934-1.047$ \\
\hline
\end{tabular}

*The anger management and stress control program.

Bold values are significant. Wald: 25,682; $P$ significant at .001 .

SCS, Self-Confident Subscale of the Styles of Stress Coping Inventory; TAS, Trait Anger Subscale of the Strait and Trait Anger Scale; HS, The Hopeless Subscale of the Styles of Stress Coping Inventory. 
in smoking cessation; participants with higher posttest scores on TAS and HS and low SCS scores were at risk for relapse. Cougle et $\mathrm{al}^{21}$ reported that anger experience was uniquely associated with a lifetime history of smoking cessation failure in 5692 adults from the National Comorbidity Survey. Early relapse is known to be a highly critical aspect of smoking cessation, and relapse rates within 2 weeks can be as high as $75 \% .^{40}$

In our study, most of the relapses occurred in the first week after cessation. Relapse rates during this period were $29.1 \%$ in the study group compared with $42.2 \%$ in the control group. It is interesting that the study group had a $22 \%$ lower relapse rate compared with the control group, although they had received only 3 sessions of the anger management and stress control program at that time. There is evidence of an association between increased trait anger and early relapse, which may be related to an increased tendency to experience situational irritants, leading to an increased craving to smoke. ${ }^{41}$ Perkins et $\mathrm{al}^{10}$ also reported that increases in anger levels after quitting were associated with relapse within 5 days. Swan et $\mathrm{al}^{11}$ detected the same relationship in 28-day relapse. Paterson et $\mathrm{al}^{20}$ more recently reported that patients $(\mathrm{n}=117)$ who had self-reported increased pre- to post-quit state anger levels compared with other subjects $(\mathrm{n}=130)$ were more prone to relapse (odds ratio $[\mathrm{OR}], 1.06$; 95\% confidence interval [CI], 1.011.10). Furthermore, smokers with increased anger after quitting relapsed almost twice as quickly as those with no increase in anger symptoms after quitting (hazard ratio, 1.98; CI, 1.32-2.96).

Specific cognitive and behavioral strategies are needed to maintain initial treatment success and minimize the rate of relapse. One such strategy is to help familiarize the patient with withdrawal symptoms and teach very basic techniques for anticipating and coping with common high-risk situations. This is used in many cessation programs. A second approach is to help the smoker promote permanent self-control. The efficiency of these 2 strategies was tested in our study. Both groups attended our standard quitting program, which uses many motivational and reinforcement strategies (face-to-face counseling, workshops, NRT, pharmacotherapy, and telephone and partner support). We provided the control group with anger management and stress control strategies for withdrawal symptoms twice, first in the workshop (group discussion) and again during the second visit (face-to-face counseling), which was on the quit day and scheduled for 10 minutes. However, the study group also spent 5 weeks in the cognitive behavioral therapy-oriented anger management and stress control program. Traditional disease-based models attribute smoking relapse to endogenous factors such as cravings or withdrawal, whereas cognitive behavioral theories emphasize contextual factors (eg, environmental stimuli and cognitive processes). ${ }^{42}$ Whether a high-risk situation culminates in relapse depends largely on the individual's capacity to exhibit an effective coping response, defined as any cognitive or behavioral compensatory strategy that reduces the likelihood of relapse. Cognitive factors involved in determining relapse liability, such as successful navigation of high-risk situations, may increase self-efficacy (the perceived capacity to cope with an impending situation or task) and thus in turn reduce the probability of relapse. Conversely, a return to the target behavior can undermine self-efficacy, increasing the risk of future relapses. ${ }^{43}$ Our program is mainly influenced by 2 different aspects that interact with one another in the relationship between smoking, anger, and stress. One aspect is smokers' use of nicotine as an ineffective and unhealthy way of coping with their anxiety, stress, and anger as a self-learned maintenance therapy. ${ }^{44,45}$ The other aspect, which is avoiding this phenomenon and promoting, perceiving, and increasing individuals' ability to select effective anger and stress coping strategies, is essential. There are 2 main ways of coping with anger and stress: problem focused and emotion focused. ${ }^{46}$ Problem-focused strategies, which we aim to promote among our participants with our program, use planned, learned activities to alter the situation that causes stress. We measured this variable with the SCS. Emotion-focused strategies are largely passive and concentrate on diminishing negative emotions, avoiding contact with stressors, and seeking psychological and social support, which we measured with the HS.

The effect of cognitive behavioral therapy on maintaining smoking cessation has recently been receiving increased attention. Thorndike et $\mathrm{al}^{47}$ reported that after 5 -session cognitive behavioral therapy, although participants' compensatory coping skills were not enhanced, the success rate in the study group was $38 \%$ compared with $22 \%$ in the control group. Kapson et al ${ }^{48}$ reported that after 8 
sessions of cognitive behavioral therapy participants' compensatory skills improved, with a success ratio of $33 \%$ over a 3 -month period. However, both these studies were designed to investigate the effects of cognitive behavioral therapy on more or less depressive-prone smokers. Agboola et $\mathrm{al}^{49}$ investigated the effects of 36 skill-based relapse prevention studies in a systematic review. Cognitive behavioral therapies with relapse-based self-help interventions had a significant effect in increasing long-term abstinence (OR, 1.52; 95\% CI, 1.152.01), and group counseling exhibited significant short-term efficacy (OR, 2.09; 95\% CI, 1.14-3.85). We calculated the effect of our anger management and stress control program on cessation at 6 months as an OR of 2.09 and a $95 \%$ CI of 1.142 to 3.852 .

Family practice mostly advocates horizontal health care services instead of longitudinal organizations (specialized centers) to deal with smoking cessation. This is particularly important in countries with a high prevalence of smoking. However, although family practitioners believe that they should recommend preventive and health-promotion activities, in practice they seem less likely to do so. ${ }^{50}$ In one large, multinational study across 11 countries $(\mathrm{n}=2082)$, Brotons et $\mathrm{al}^{51}$ found that family practitioners regard a heavy workload, shortage of time, and lack of financial reimbursement as the main barriers to health promotion activities. Lack of adequate training and acquisition of proper skills for smoking cessation also are noted as barriers. Werner et $\mathrm{al}^{52}$ reported that more than half $(57 \%)$ of family practitioners $(n=73)$ were using nonadherent motivational interviewing techniques when dealing with patients. Lack of motivation, training, support, educational resources, and protocols; concerns over low success rates; and failure to use the skills of the members of the primary care unit were identified as barriers to prevention activities on the part of family physicians. Family practitioners need highly successful, not time-consuming, easy-to-maintain, well-designed, collaborative health promotion activities. Our study revealed that the anger management and stress control program is more time/cost-effective compared to the individual approach (our clinic's standard treatment program). For the same amount of smokers (175 each) the same amount of time is required, however, the quit rates of patients who participated the anger management and stress con- trol program are far higher. Calculated for a total of 175 participants, to achieve a $27.4 \%$ quit rate for the control group, we need 440 work hours compared with a $44 \%$ quit rate for approximately 420 work hours in the study group over 6 months.

Our study may have some weaknesses. One is the number of the participants. The behavioral therapies group sessions described were designed for no more than 20 participants (14 to 15 would be ideal), and there was only one therapy team available to teach them. This limited the number of participants. The other issue is isolating the effect of our program on smoking cessation. It is debatable whether the outcomes of the control group would have been better (quit rates and decrease in TAS, SCS, and HS post-test results) if they had received other types of group therapy on a different topic instead of individual follow-up. As described, in our standard program (control groups' treatment program) we also discuss anger management and stress control (tips, facts, and strategies) with all our participants at least twice (in the group during a workshop and individually during the second visit) for approximately 20 minutes each. Another design to isolate the effect would be to apply anger management and stress control activities individually or during group therapy. Cognitive behavioral therapy always works best with groups, so we decided to design our study in this way. The second dimension is the participants in both groups who used several techniques and medication types to quit smoking (BC, NRT, bupropion, or varenicline). As discussed earlier, NRT eased the effects of anger and stress, whereas varenicline and bupropion are mood modulators. Although participants who used varenicline in the study and control groups had better quit rates compared with smokers treated with BC and NRT in the control groups, the quit rates according to treatment type were not significant in the study group. It can be assumed that participation in the anger management and stress control program boosted the cessation effect of all the methods used in the study group. This may be attributed to several factors. The cessation effects of BC, NRT, bupropion, and varenicline are known to decrease in the mid- and long-term. ${ }^{50} \mathrm{In}$ addition to the content of the anger management and stress control program applied to the study group, we used several different individual or group cessation techniques in both our groups (eg, selfhelp booklet, telephone consultation, face-to-face 
behavioral counseling). Another factor is that all the participants were highly motivated and directly sought help to quit smoking by applying to our departmental clinic. It is also possible that smokers with higher trait anger and worse ability to cope with stress might benefit more from this program.

\section{Conclusion}

The cognitive behavior-oriented anger management and stress control program had positive effects on reducing relapse rates. Cognitive behavioral therapy is a promising approach for smoking cessation activities. Further data are needed to investigate the effects of this kind of intervention in the short, mid-, and long term.

\section{References}

1. Mcllfatrik S, Keeney S, Mckenna H, McCarley N, Mcllwee G. Investigating the role of the general practitioner in cancer preventation: a mixed methods study. BMC Fam Pract 2013;14:58.

2. McAvoy BR, Kaner EF, Lock CA, Heather N, Gilvarry $\mathrm{E}$. Our healthier nation: are general practitioners willing and able to deliver? A survey of attributes to and involvement in health promotion and life style counseling. Br J Gen Pract 1999;49:187-90.

3. McEwan A, West R. Smoking cessation activities by GP and practice nurses. Tob Control 2001;10:27-32.

4. Ferguson J, Bauld L, Chesterman J, Judge K. The English smoking treatment services: one-year outcomes. Addiction 2005;100:59-69.

5. Nakajima M, al'Absi M. Predictors of risk for smoking relapse in men and women: a prospective study. Psychol Addict Behav 2012;26:633-7.

6. Lee CW, Kahende J. Factors associated with successful smoking cessation in the United States, 2000. Am J Public Health 2007;97:1503-9.

7. Brown AK, Mandelkern MA, Farahi J, et al. Sex differences in striatal dopamine D2/D3 receptor availability in smokers and non-smokers. Intl J Neuropsychopharmacol Smith SM, Rogers RD, Matthews PM, Walton RT 2012;15:989-94.

8. David SP, Munafò MR, Johansen-Berg H, et al. Ventral striatum/nucleus accumbens activation to smoking-related pictorial cues in smokers and nonsmokers: a functional magnetic resonance imaging study. Biol Psychiatry 2005;15:58:488-94.

9. Kassel JD, Stroud LR, Paronis CA. Smoking, stress, and negative effect: correlation, causation, and context across stages of smoking. Psychol Bull 2003;129: 270-304.

10. Perkins KA, Grobe JE, Caggiula A, Wilson AS, Stiller RL. Acute reinforcing effects of low dose nicotine nasal spray in humans. Pharmacol Biochem Behav 1997;56:235-41.
11. Swan GE, Ward MM, Jack LM. Abstinence effects as predictors of 28-days relaps in smokers. Addict Behav 1996;21:481-90.

12. Litvin EB, Kovacs MA, Hayes PL, Brandon TH. Responding to tobacco craving: experimental test of acceptance versus suppression. Psychol Addict Behav 2012;26:830-7.

13. Gilbert DG, McClernon FJ, Rabinovich NE, et al. Mood disturbance fails to resolve across 31 days of cigarette abstinence in women. J Consult Clin Psychol 2002;70:142-52.

14. Kalman D. The subjective effects of nicotine: metodological issues, a review of experimental studies, and recommendations for future research. Nicotine Tob Res 2002;4:25-70.

15. Gilbert DG, Gilbert BO. Personality, psychopathology, and nicotine response as mediators of the genetics of smoking. Behav Genet 1995;25:133-47.

16. Picciotto MR. Common aspects of the action of nicotine and other drugs of abuse. Drug Alcohol Depend 1998;51:165-72.

17. Koob GF, Le Moal M. Drug abuse and dysregulation of reward and allostasis. Neuropsychopharmacology 2001;24:97-129.

18. Gilbert DG, Rabinovich NE, Malpass D, et al. Effects of nicotine on effect are moderated by stressor proximity and frequency, positive alternatives, and smoker status. Nicotine Tob Res 2008;10:1171-83.

19. al'Absi M, Carr SB, Bongard S. Anger and psychobiological changes during smoking abstinence and in response to acute stress: prediction of smoking relaps. Int J Psychophysiol 2007;66:109-15.

20. Patterson F, Kerrin K, Wileyto EP, Lerman C. Increase in anger symptoms after smoking cessation predicts relaps. Drug Alcohol Depend 2008;95: 173-6.

21. Cougle JR, Zvolensky MJ, Hawkins KA. Delineating a relationship between problematic anger and cigarette smoking: a population-based study. Nicotine Tob Res 2013;15:297-301.

22. Zvolensky MJ, Bernstein A, Cardenas SJ, et al. Anxiety sensitivity and early relapse to smoking: a test among Mexican daily, low-level smokers. Nicotine Tob Res 2007;9:483-91.

23. West R, McEwen A, Bolling K, Owen L. Smoking cessation and smoking patterns in the general population: a 1-year follow-up. Addiction 2001;96:891902.

24. Brown RA, Lejuez CW, Kahler CW, Strong DR, Zvolensky MJ. Distress tolerance and early smoking lapse. Clin Psychol Rev 2005;25:713-33.

25. Rao PR. Emotional intelligence: the Sine Qua Non for a clinical leadership toolbox. J Commun Disord 2006;39:310-9.

26. Hughes JR, Keeley JP, Niaura R, Ossip-Klein DJ, Richmond RL, Swan GL. Measure of abstinence in clinical trials: issues and recommendations. Nicotine Tob Res 2003;5:13-25. 
27. Cahill K, Stevens S, Perera R, Lancaster T. Pharmacological interventions for smoking cessation: an overview and network meta-analysis. Cochrane Database Syst Rev 2013;5:CD009329.

28. Stead LF, Buitrago D, Preciado N, Sanchez G, Hartmann-Boyce J, Lancaster T. Physician advice for smoking cessation. Cochrane Database Syst Rev 2013;5:CD000165.

29. National Institute for Health and Clinical Excellence. Smoking cessation services. Quick reference guide, 2008. Available from: www.nice.org.uk/PH010. Accessed July 20, 2014.

30. Hartmann-Boyce J, Lancaster T, Stead LF. Printbased self-help interventions for smoking cessation. Cochrane Database Syst Rev 2014:6:CD001118.

31. Lai DT, Cahill K, Qin Y, Tang JL. Motivational interviewing for smoking cessation. Cochrane Database Syst Rev 2010;20:CD006936.

32. Yalcin BM, Karahan TF, Ozcelik M, Igde FA. The effects of an emotional intelligence program on the quality of life and well-being of patients with type 2 diabetes mellitus. Diabetes Educ. 2008; 34:1013-24.

33. Heartherton TF, Kozlowski LT, Frecker RC, Fagerström KO. The Fagerstrom test for nicotine dependency: a revision of the Fagerstrom Tolerance Questionnaire. Br J Addict 1991;86:1119-27.

34. Spielberger CD, Johnson EH, Russel FS, Crane RS, Jacobs GA, Worten TJ. The experience and expression of anger: construction and validation of an Anger Expression Scale. In: Chesney MA, Roseman RH (eds.). Anger and hostility in cardiovascular and behavioural disorders. New York: Hemshire/McGrawHill; 1985:5-30.

35. Ozer AK. The prestudy of State Anger and Expression of Anger Scales. J Turkish Psychol 1994;31:26-35.

36. Folkman S, Lazarus RS. An analysis of coping in a middle-aged community sample. J Health Soc Behav 1980;21:219-39.

37. Sahin NH, Durak A. The adaptation of the stress coping styles inventory to the university students. J Turkish Psychol 1995;10:56-73.

38. Delfino RJ, Jamner LD, Whalen CK. Temporal analysis of the relationship of smoking behavior and urges to mood states in men versus women. Nicotine Tob Res 2001;3:235-48.

39. Jamner LD, Shapiro D, Jarvik ME. Nicotine reduces the frequency of anger reports in smokers and non- smokers with high but not low hostility: an ambulatory study. Exp Clin Psychopharmacol 1999;7:454-63.

40. Law M, Tang JL. An analysis of the effectiveness of interventions intended to help people stop smoking. Arch Intern Med 1995;155:1933-41.

41. Kahler CW, Strong DR, Niaura R, Brown RA. Hostility in smokers with past major depressive disorder: relation to smoking patterns, reasons for quitting, and cessation outcomes. Nicotine Tob Res 2004;6: 809-18.

42. Handershot CS, Witkietwitz K, George WH, Marlatt GA. Relapse prevention for addictive behaviors. Subst Abuse Treat Policy 2011;6:17.

43. Piasecki TM. Relapse to smoking. Clin Psychol Rev 2006;26:196-215.

44. Picciotto MR, Brunzell DH, Caldarone BJ. Effect of nicotine and nicotinic receptors on anxiety and depression. Neuroreport 2002;13:1097-106.

45. Lawrence D, Mitrou F, Zubrick SR. Non-specific psychological distress, smoking status and smoking cessation: United States National Health Interview Survey 2005. BMC Public Health 2011;11:256.

46. Folkman S, Lazarus RS, Gruen RJ, DeLongis A. Appraisal, coping, health status, and psychological symptoms. J Pers Soc Psychol 1996;50:571-9.

47. Thorndike FP, Friedman-Wheeler DG, Haaga DA. Effect of cognitive behavior therapy on smokers' compensatory coping skills. Addict Behav 2006;31: 1705-10.

48. Kapson HS, Leddy MA, Haaga DA. Specificity of effects of cognitive behavior therapy on acceptance and distress tolerance in a randomized control trial for smoking cessation. J Clin Psychol 2012;68:1231-40.

49. Agboola S, McNeill A, Coleman T, Leonardi Bee J. A systematic review of the effectiveness of smoking relapse prevention interventions for abstinent smokers. Addiction 2010;105:1362-80.

50. Yarnal K, Pollak K, Østby T, Karuse KM, Michener JL. Primary care: is there enough time for prevention? Am J Public Health 2003;93:635-41.

51. Brotons C, Björkelund C, Bulc M, et al. Prevention and health promotion in clinical practice: the views of general practitioners in Europe. Prev Med 2005; 40:595-601.

52. Werner JJ, Lawson PJ, Panaite V, Step MM, Flocke SA. Comparing primary care physicians' smoking cessation counseling techniques to motivational interviewing. J Addict Med 2013;7:139-42. 
Appendix 1. The Agenda of The Anger Management and Stress Control Program

\begin{tabular}{lcc}
\hline Main Theme By & & Techniques and Tools \\
Session & Time & Content \\
\hline
\end{tabular}

First session

90 minutes

"To form a group"

Second session

90 minutes

"Identify your anger"

Third session

90 minutes

"Choice is yours"

Fourth session

90 minutes
First half (45 minutes): After a warm-up, "Introduction Game" was played; members were introduced to one another and were also told about the aim of the program, the duration and frequency of the sessions, the privacy contract applicable in the group, how the group would work, the rules to be obeyed in the group; and the rules surrounding attendance.

Second half (45 minutes): Sharing those experiences and situations that most angered members with the group; sharing experiences such as behaving unrestrainedly, psychic attack, displaying subsequent regret for the damage that anger does to relations, taking alcohol, smoking, overeating, or drug use in times of anger, or facing legal problems as a result of anger, and role play. The group participated in the game "The Things That Make Me Angry" Homework: the group members asked to list things that made them angry. The session finished with the "Deadlock Game."

First half (45 minutes): Identifying clues to anger and its psychic, emotional, and behavioral symptoms, with the aim of controlling anxiety, training in relaxation and breathing correctly, the ability to use relaxation in daily life. The group participated in the "Anger Machine" game.

Second half (45 minutes): The group discussed the previous session's homework and the ability to perceive negative feelings once they arise and the attribute of awareness.

Homework: the group members exchanged the former sessions' homework and propositions on how to avoid them. The group participated in the warming game "Acting a Feeling" (Schilling, 1996). Evaluating the states of being aware or not being aware of the basic feelings experienced in the face of negative events.

First half (45 minutes): To comprehend the "Theory of Election" and attain the ability to use it with the aim of anger control; taking responsibility for behavior displayed at the time of anger and giving examples from personal experience. A group forum took place at which the Election Theory was discussed.

Second half (45 minutes): The group discussed the previous session's homework and the ability to define a strategy related to managing feelings of anger and the ability to implement that strategy; identifying, exemplifying, practicing and role playing various strategies such as cognitive reconstruction, changing the environment and using humor, communicating effectively, sharing feelings, and perceiving cognitive distortions. Relaxation repetition.

Homework: What is your favorite relaxation method?

First half (45 minutes): Expressing anger and negative feelings using "I language"; practice, role play, and relaxation repetition; the role of music to relieve the anger and stress.
Warm-up surveys

Active presentation

Handouts

Small-group

discussion

Role plays

Workshop

Warm-up

Homework

Music listening with

breath exercise

Active presentation

with discussion

Handouts

Small-group

discussion on topic

Role plays

Workshop

Warm-up

Homework

Music listening with

breath exercise

Active presentation with discussion

Handouts

Small-group

discussion on topic

Warm-up

Homework

Music listening with breath exercise 


\section{Appendix 1. Continued}

\begin{tabular}{|c|c|c|c|}
\hline $\begin{array}{l}\text { Main Theme By } \\
\text { Session }\end{array}$ & Time & Content & $\begin{array}{c}\text { Techniques and Tools } \\
\text { Used }\end{array}$ \\
\hline "Express yourself" & & $\begin{array}{l}\text { Second half ( } 45 \text { minutes): The group discussed the } \\
\text { previous session's homework and using the ability to } \\
\text { listen effectively by way of eye contact with the } \\
\text { person one is angry with; realizing the reactions to } \\
\text { poor listening, practice, role play, and relaxation } \\
\text { repetition. } \\
\text { Homework: create a situation with a friend of } \\
\text { yourself which made you angry or stressed. }\end{array}$ & $\begin{array}{l}\text { Active presentation with } \\
\text { discussion } \\
\text { Handouts } \\
\text { Small-group } \\
\text { discussion on topic }\end{array}$ \\
\hline Fifth session & 90 minutes & $\begin{array}{l}\text { First half ( } 45 \text { minutes): Giving reactions intended to } \\
\text { maintain communication during conflict and in } \\
\text { times of anger, understanding other people's feelings } \\
\text { by developing empathy. Practicing and role-playing. }\end{array}$ & $\begin{array}{l}\text { Warm-up } \\
\text { Homework } \\
\text { Music listening with } \\
\text { breath exercise }\end{array}$ \\
\hline $\begin{array}{l}\text { "I am empathetic, you } \\
\text { are empathetic" }\end{array}$ & & $\begin{array}{l}\text { Second half ( } 45 \text { minutes): The former sessions' } \\
\text { homework is dispatched to other members and } \\
\text { asked to role play with a group member to find an } \\
\text { effective solution to the scenario. The group's } \\
\text { feelings and experiences were shared, and the } \\
\text { program was evaluated with the members. The } \\
\text { program came to an end with the game of "Building } \\
\text { Ego" and relaxation exercises. }\end{array}$ & $\begin{array}{l}\text { Active presentation with } \\
\text { discussion } \\
\text { Handouts } \\
\text { Small-group } \\
\text { discussion on topic }\end{array}$ \\
\hline
\end{tabular}

